\title{
Low-cost carrier entry at small European airports: Low-cost carrier effects on network connectivity and self-transfer potential
}

\author{
Patrick Zeigler, Romano Pagliari, Pere Suau-Sanchez, Paolo Malighetti, Renato Redondi
}

\begin{abstract}
Airport connectivity can improve the competitiveness of regions by attracting tourism and inward investment. Regions traditionally accessed international destinations via connecting flights to national gateway airports usually operated by full service network carriers (FSNC). However, the entry of low-cost carriers (LCC) in these markets has led to changes in incumbent FSNC service provision. We analyse how intra-European connectivity has changed at small airports between 2002 and 2012 and how LCC entry has affected the quality of day-return schedules in these markets. Results show that offline LCC connectivity is greater than that scheduled by FSNCs. Furthermore, LCC entry had a negative effect on the quality of the connectivity offered by FSNCs. Interestingly, we also found that day-return itineraries become more difficult for passengers in markets where the LCC is the sole operator. Regional policy-makers may need to more carefully consider the connectivity implications in the design of LCC start-up incentive schemes.
\end{abstract}

\section{Key Words}

Connectivity; airports; LCC entry, Europe

\section{Introduction}

Airport connectivity is a way of measuring how accessible a region is in terms of its air transport links. High levels of connectivity have the potential to deliver significant economic and social benefits to both cities and regions (Goetz, 1992; Brueckner, 2003; Bel and Fageda, 2008; van de Vijver et al., 2014; Florida et al., 2015). When regions are disadvantaged by their location relative to major metropolitan and economic centres, frequent links to hubs that offer numerous onward destinations enhances connectivity (Suau-Sanchez and Burghouwt, 2012); this can improve the competitiveness of a region in attracting tourism and inward investment as it facilitates face-to-face interactions (Gaspar and Glaeser, 1998; Hall, 2009).

Connectivity depends on a diverse range of factors, such as, the types of airlines operating at an airport and the scale and geographic scope of their network. Connectivity offered by full service network carriers (FSNC), for example, can be quite different to that offered by a low-cost carrier (LCC). The former coordinates schedules at hub airports, offering seamless connections between regional, national, intracontinental and global markets. The latter, in contrast, limit themselves to serving short-haul markets only. Although some LCCs are evolving and offer connecting flights (Fageda et al., 2015), most LCCs, in order to maintain cost-competitiveness, focus on point-to-point services and do not facilitate connecting traffic. This enables them to schedule services competitively against incumbents without being subject to the complexities associated with a connecting wave-system (Fageda et al., 2015). Yet, in a context where low-cost carriers have rapidly become the dominant players in the short-haul markets (Dobruszkes, 2013), the substantial amount of flight frequencies at low-cost airport bases have created opportunities 
to transfer between those flights, even though flight connection services are not typically offered by the low-cost carriers themselves (Malighetti et al, 2008; Maertens et al., 2016). Passengers that do wish to connect between an LCC's flights must self-transfer, enduring the inconvenience of an additional check-in process at the LCC airport base, and facing the added risk of a missed connection. In spite of this, an increasing number of passengers self-transfer, especially among price-sensitive air travellers ( $O^{\prime}$ Connell and Williams, 2005, OAG 2016). In spite of that, only few airports in the world actively support selfconnections. Examples include London Gatwick and Milano Malpensa airports, which have introduced the GatwickConnects and ViaMilano platforms, respectively. These allow passengers to book online their own flight transfer services between two flights not explicitly connected by the airline/s involved. In exchange for a fee (Gatwick) or for free (Milano), self-connecting passengers are offered a baggage transfer service and insurance against the risk of missing their onward flights.

Communities located in smaller regions have traditionally been able to access international destinations via connecting flights scheduled to their main national gateway usually operated by FSNCs or their regional affiliates (Suau-Sanchez, et al., 2014). However, since the deregulation of the European air transport market, LCCs have launched services from many regional airports, growing traffic volumes and expanding the number of destinations served. FSNCs operating in regional markets have often had to reduce or even withdraw services as a result of LCC competition. Whilst it could argued that LCCs reduce the cost of travel for passengers (Fageda and Fernandez-Villadangos, 2009), the seamlessness and integration that FSNC networks provide between regional and international markets can disappear. However, Malighetti et al. (2008) highlights that two-thirds of the fastest indirect connections in Europe are not operated by FSNC, but by other carriers; this opportunity could be exploited to enable higher levels of connectivity.

Against this background, we contribute to the literature on the connectivity effects of LCC entry at small airports in two ways. Firstly, we analyse how intra-European connectivity has changed at small airports over the period 2002 to 2012 and what has been the effect, if any, of LCC expansion in these markets. Secondly, we evaluate how LCC entry has affected the quality of schedules for day-return trips, focusing on links between small airports and metropolitan centres. These connections are essential in facilitating face-to-face interaction and the continued sustainability of businesses located in non-metropolitan regions (Pagliari, 2003). The analysis also focuses on the role played by the remoteness of markets and the distance to main city centres, which result in the unevenness of connecting options across the Europe.

The reminder of the paper is structured as follows: in Section 2 we discuss the literature on airport connectivity at small airports. Section 3 presents the data sources, the airport grouping and methodology. Section 4 presents the results and Section 5 discusses the implications for both policy and practice.

\section{Airport connectivity at small airports}

2.1 The concept of airport connectivity and ways to measure it 
Traditionally, measuring airport connectivity has been a way of quantifying how accessible a region is in terms of air transport links. Every passenger perceives their individual connection from origin to destination differently and choses the airline and route according to individual preferences (CastilloManzano and Marchena-Gomez, 2011; Nassiri and Rezaei, 2012). Intuitively, for a passenger, the most direct and fastest connection would be the most preferred. However other variables will also have an effect on how passengers select their travel itinerary. For instance, a lower ticked price or high brand loyalty to an airline may also influence the itinerary choice and for these reasons, passengers may be willing to endure the inconvenience of a transfer at an intermediate hub in preference to a direct service. However, as a general rule, the most preferred connection between two airports is when both the total travel time and the number of interim stops is minimised. Airlines will aim to facilitate point-to-point demand with direct flights. However, in low traffic density markets, direct flights may not be commercially feasible, so connecting flights via a hub will be scheduled to meet travel demand. For a small airport, direct services to and from a hub can significantly increase connectivity (Button, 2002; Redondi et al., 2011), since the increase in the number of airports served from the hub impacts exponentially on the number of city-pairs served (Doganis, 2010).

There are diverse ways to measure airport connectivity. Burghouwt and Redondi (2013) and Suau-Sanchez et al. (2015) provide a thorough review of the different approaches and studies on airport connectivity.

On the one hand, supply-based studies, i.e., analyses using airline supply data, such as flight schedules, use accessibility and centrality measures. The former provides information on potential connectivity by measuring the maximum number of potential connections available to each arriving flight, the latter, calculates the centrality of each airport based on the topology of the network (centrality models). The main supply-based accessibility measures are, among others, the Danesi measure (Danesi, 2006), the Reynolds-Feighan and McLay accessibility approach (Reynolds-Feighan and McLay, 2006), the Netscan model (Veldhuis, 1997; Matsumoto et al., 2008; Suau-Sanchez-Burghouwt, 2012), the Weighted Indirect Connections (Burghouwt and de Wit, 2005; Burghouwt, 2007), and the Accessibility index (Redondi et al., 2013). The main supply-based centrality measures are degree centrality (Bowen, 2000; Burghouwt and Hakfoort, 2001), betweeness centrality (Guimerà et al., 2005; Guida and Maria, 2007; Malighetti et al., 2008; Paleari et al., 2010), closeness centrality (Sapre and Parekh, 2011), essential betweeness centrality (Malighetti et al., 2008), weighted betweeness (Rodriguez-Deniz, 2012), and average quickest travel time (Niesse and Grimme, 2013). Since these studies are based on the analysis of published airline schedules, their results can be interpreted in terms of potential "flight connectivity" rather than actual "passenger connectivity". An important limitation of this approach is that not all flight connectivity has the same value for the airports and airlines involved. Potential connections in large city-pair routes will be more valuable than in city-pair routes where no passenger traffic is recorded.

Addressing this limitation requires the use of data on passenger bookings that have explicit indication on the actual city-pair market that is being connected and the actual full passenger itinerary (e.g., MIDT and PaxIS are two of the most well-known databases). These demand-based studies use centrality measures and provide information on the actual topology of the network. The main measures are hub intensity 
(Derudder et al., 2010), degree and betweeness centrality (Wang et al., 2011; Zeng et al., 2011, Jia and Jiang, 2012), closeness centrality (Wang et al., 2011), connecting passengers (Adikariwattage et al., 2012) and flow centrality (Rodríguez-Déniz et al., 2013; Suau-Sanchez et al., 2015, 2016a).

\subsection{Uneven connectivity at small airports}

Studies on small and remoter airports have generally been focused on the provision of air services and their economic impact, the different subvention mechanisms and infrastructure requirements (see, for example, Williams and Bråthen, 2010). But research on accessibility and connectivity of remoter airports has been limited. Recent contributions share the view that there is an uneven distribution of connectivity among smaller airports. Halpern and Bråthen (2011), with reference to Norway, highlight that frequency levels are higher to domestic destinations compared to international. Similarly, Suau-Sanchez and Burghouwt (2012), in analysing the Spanish market, demonstrate that only the smaller airports connected to the main national hub could achieve significant connectivity values to international destinations. At the European level, Suau-Sanchez et al. (2016a) shows that only a limited number of European airports benefited significantly from deregulation and LCC traffic development. Furthermore, those airports that benefitted from connectivity improvements were usually dependent on a small number of airlines, in most cases, Ryanair. Similar observations were made by Lian and Rønnevik (2011) who showed that LCC entry in Norway also led to a loss of traffic at smaller regional airports. The results of the studies mentioned above are confirmed by a Europe-wide analysis (Lieshout, et al., 2016) which highlights that in large parts of Scandinavia, France and Spain, airline and airport competition is considerably limited and affects connectivity opportunities. These areas are often served only by a handful of airports and/or airlines, limiting airline choice and therefore competition. In addition, the small size of airports and the limited traffic and connectivity also impacts on their efficiency. In this regard, Merkert and Mangia (2014) show that regional and small airports with low levels of competition also deliver lower efficiency levels.

While most of the literature focuses on historical dimensions, Redondi et al. (2013) considers the effects of future scenarios on connectivity by simulating effects caused by the closure of airports handling less than 2 million passengers a year. The study found relatively limited country-level effects, with the exception of the Scandinavian states, and significant variation between regions. For example, some regions in France, Spain and Italy experienced increases in average travel times of up to $40 \%$.

Furthermore, the phenomenon of self-connectivity that was firstly defined by Burghouwt (2007) as "selfhelp hubbing" and was later analysed by Malighetti et al. (2008) for smaller airports. They highlight the opportunities this offers in connectivity terms, they results show that two-thirds of the fastest indirect connections in the intra-European market are not operated by carriers aligned to alliance networks. Other studies have scoped the market potential of self-connectivity (Fitchert and Klophaus, 2016; Maertens et al., 2016; Suau-Sanchez et al., 2016b), but with less emphasis on the potential benefits for smaller airports. 
3.1 The sample of airports

We obtain our data from the OAG (Official Airline Guide) dataset, which provides supply information on a diverse number of variables for each scheduled flight, including origin and destination airport, time of departure and arrival, number of seats supplied, aircraft type, and day of operation. OAG Schedules only provide information on supplied capacity and not demand, such as for example, the connections that passengers might have to undertake via specific hubs. We include intra-European traffic data from the second week of September for the years 2002 to 2012. We consider the EU-28, plus Norway and Switzerland.

Our study focuses on small airports. In selecting the airports, we considered two dimensions: size and location. Regarding the former, we considered all those airports that handled less than 4 million passengers. Although other studies consider lower values1, we believe that given increasing airport polarisation in Europe, it is important to analyse not only airports in the lowest tier, but also those in the lower part of the mid-tier. Also, considering that we have a second sample constraint, i.e., location, the sample would have become too small if we would have considered a lower threshold. Concerning the location factor, we only considered those small airports that are located greater than $100 \mathrm{~km}$ from another airport. A distance of $100 \mathrm{~km}$ could be still considered to be relatively short, but this needs to be put into perspective as different countries have different travel patterns. According to analysis by the Office for National Statistics (2014) the mean Euclidean distance travelled to work in England and Wales in 2011 was $15 \mathrm{~km}$. In addition, 83\% of the journeys were under 20km (Rae, 2016). These values are different from those in the US, where the commuting tolerance is $45 \mathrm{~min}$ (Clark et al., 2003) and where long distance commuters can tolerate around 80km (Rapino, and Fields, 2012; Dash Nelson and Rae, 2016). These values, clearly influence the perspective of the passenger on distance and the different understandings of functional urban regions.

In this regard, previous studies looking into catchment areas and functional airport regions use a diverse range of distances. Kasarda (2000) defines the Aerotropolis influence area at the $25 \mathrm{~km}$ radius. Arend et al (2004) define at $50 \mathrm{~km}$ the broad interpretation of Aerotropolis, the same distance defined by Van Wijk (2007) for defining the city-port functional region for Europe. Knippenberger (2010) considers that an airport functional region in Germany could stretch up to an $80 \mathrm{~km}$ radius. Finally, the European Commission considers that the typical catchment area would not be beyond $100 \mathrm{~km}$ driving distance (Copenhagen Economics, 2012). Other studies, e.g., Suau-Sanchez et al. 2014, have also looked into the different catchment areas radius (25, 50 and $100 \mathrm{~km})$. Hence, by considering a distance greater than $100 \mathrm{~km}$ the selected airports should be outside the typical European airport catchment area.

\footnotetext{
${ }^{1}$ We acknowledge that other studies considered lower thresholds. Redondi et al. (2013) consider only airports below 2 million passengers. Suau-Sanchez et al. (2015b) when classifying the European airports in categories, considered airports below 2.5 million passengers a year for the smallest tier. Burghouwt (2007) was more restrictive and only considered airports with less than 0.3 million passengers a year for the smallest airport-tier.
} 
We acknowledge, however, that there are limitations in considering a homogenous distance threshold for all airports in the sample. The potential of an airport's market will depend on basic features of the region where it is located (e.g., amount of population in the area, their propensity to fly, economic activities, airport access time), airport related factors (e.g., network supplied by the airlines) and airport competition (Suau-Sanchez et al., 2014). Indeed, most studies show that airport choice is largely determined by access time, flight frequency and/or airfares (Pels et al., 2001, 2003; Hess and Polak, 2005, 2006; Zhang and Xie, 2005; Lieshout, 2012). However, this is information not available to us and out of the scope of this study.

The airport sample is classified in three groups or types. The first type were those that experienced, in the period 2002 to 2012, LCC entry on routes already served by a FSNC connection to a major hub. The second type of airport included those in which a low-cost carrier started services to non-hub destinations2. The third type includes airports that maintained a FSNC service to a hub throughout the period of analysis and did not experience any LCC entry. See Table 1 for the complete list of airports.

The map in Figure 1 presents each airport's location relative to their respective national hubs and the four primary European gateways. We distinguish between those airports handling greater than and less than 1 million passengers in 2011. Most airports are located within $200 \mathrm{~km}$ of an alternative airport offering scheduled services with the exception of Bodoe, Trondheim, Ostersund and Cagliari. We were, however, able to obtain more meaningful sample-sizes by segregating our airports into those defined as "more remote" and "less remote". We define the threshold has being within (less remote) or beyond (more remote) $200 \mathrm{~km}$ driving distance from the nearest airport that offers direct flights by any one of the four major European FSNCs via their respective hubs 3 . Using this definition, 14 airports were classified as more remote and 18 as less remote (see Table 1). The more remote airports include for example, Lamezia (Italy) where long surface journey is needed to access hub feeder services offered at Rome Fuimicino by the 4 major FSNC networks. In contrast, residents of Memmingen (Germany), have a driving distance lower than 200km to access top 4 FSNC feeder services offered at Munich.

\footnotetext{
${ }^{2}$ We define hub airports as those where a FSNC (i.e., an airline integrated in one of the international alliances) has a dominant position and moves a high amount of connecting traffic. Non-hub airports are those that are not hubs.

${ }^{3}$ Defined as services operated by British Airways, KLM, Air France and Lufthansa and their partners to their respective primary hub airports at London Heathrow, Amsterdam, Paris Charles de Gaulle and Frankfurt.
} 
Table 1: Airports included in the analysis.

\begin{tabular}{lll}
\hline Airport Country & Passengers in \\
& $2011(000)$
\end{tabular}

\begin{tabular}{|c|c|c|c|c|c|}
\hline \multicolumn{6}{|c|}{ Type 1: LCC entry in routes served by FSNC } \\
\hline Alghero & Italy & 1,387 & & $\checkmark$ & \\
\hline Almeria & Spain & 783 & & $\checkmark$ & \\
\hline Asturias & Spain & 1,351 & & $\checkmark$ & \\
\hline Bari & Italy & 3,398 & & $\checkmark$ & \\
\hline Biarritz & France & 990 & & & $\checkmark$ \\
\hline Bilbao & Spain & 4,034 & & & $\checkmark b$ \\
\hline Bodoe & Norway & 1,612 & & & \\
\hline Brest & France & 909 & & $\checkmark$ & \\
\hline Brindisi & Italy & 1,606 & & $\checkmark$ & \\
\hline Cagliari & Italy & 3,438 & & $\checkmark$ & \\
\hline Cork & Ireland & 2,418 & & $\checkmark$ & $\checkmark$ \\
\hline Girona & Spain & 2,992 & & & $\checkmark$ \\
\hline Inverness & UK & 530 & & & $\checkmark$ \\
\hline Kerry & Ireland & 311 & & & $\checkmark$ \\
\hline Oulu & Finland & 700 & $\checkmark$ & & \\
\hline Santiago de Compostela & Spain & 2,453 & & & $\checkmark$ \\
\hline Trondheim & Norway & 3,523 & & & $\sqrt{b}$ \\
\hline \multicolumn{6}{|c|}{ Type 2: LCC services to non-hub airports } \\
\hline Beziers & France & 194 & & & $\checkmark$ \\
\hline Bydgoszcz & Poland & 278 & & & $\checkmark$ \\
\hline Dinard & France & 123 & & & $\checkmark$ \\
\hline La Rochelle & France & 192 & $\checkmark$ & & \\
\hline Lamezia & Italy & 2,301 & $\checkmark$ & & \\
\hline Luebeck & Germany & 538 & & & $\checkmark$ \\
\hline Memmingen & Germany & 765 & & & $\checkmark$ \\
\hline Poznan & Poland & 1,419 & & & $\checkmark b$ \\
\hline Rzeszow & Poland & 454 & & & $\checkmark$ \\
\hline Tours & France & 120 & $\checkmark$ & & \\
\hline \multicolumn{6}{|c|}{ Type 3: FSNC service to a hub was maintained and no LCC entry } \\
\hline Dresden & Germany & 1,843 & & & $\sqrt{b}$ \\
\hline Exeter & UK & 744 & & & $\checkmark$ \\
\hline Norwich & UK & 426 & & & $\checkmark$ \\
\hline Oestersund & Sweden & 361 & $\checkmark$ & & \\
\hline Zadar & Croatia & 275 & $\checkmark$ & & \\
\hline
\end{tabular}

a We define more or less remote airports based on whether they are located below or above $200 \mathrm{~km}$ from another airport that is linked with services offered by any one of the following FSNCs via their respective primary hub airports: British Airways, Air France, KLM and Lufthansa.

b Even though the airport may be remote as defined in note a, scheduled services are also offered by either British Airways, Air France, KLM or Lufthansa via their respective hubs in addition to a FSNC feeder service to the national hub.

In terms of distance relative to each airport's respective national bubs we find considerable heterogeneity in the sample. Some of the airports are quite remote with long driving distances to their respective national hubs (Inverness $(895 \mathrm{~km})$, Bodoe $(776 \mathrm{~km})$, Beziers $(778 \mathrm{~km})$, Oestersund $(523 \mathrm{~km})$ and Oulu $(600 \mathrm{~km}))$. Alghero and Cagliari are separated from the Italian mainland by sea crossings that are 12 to 15 hours in duration. In contrast, we have shorter distances between Poznan $(309 \mathrm{~km})$, Rzeszow $(293 \mathrm{~km})$, Cork $(259 \mathrm{~km})$ and their respective national gateways. There are some large -sized airports that are located in regions where population densities are low; this reflects high propensities to use air services amongst local citizens (e.g. Bodoe, Trondheim) and significant volumes of in-bound tourist traffic (Cagliari). 


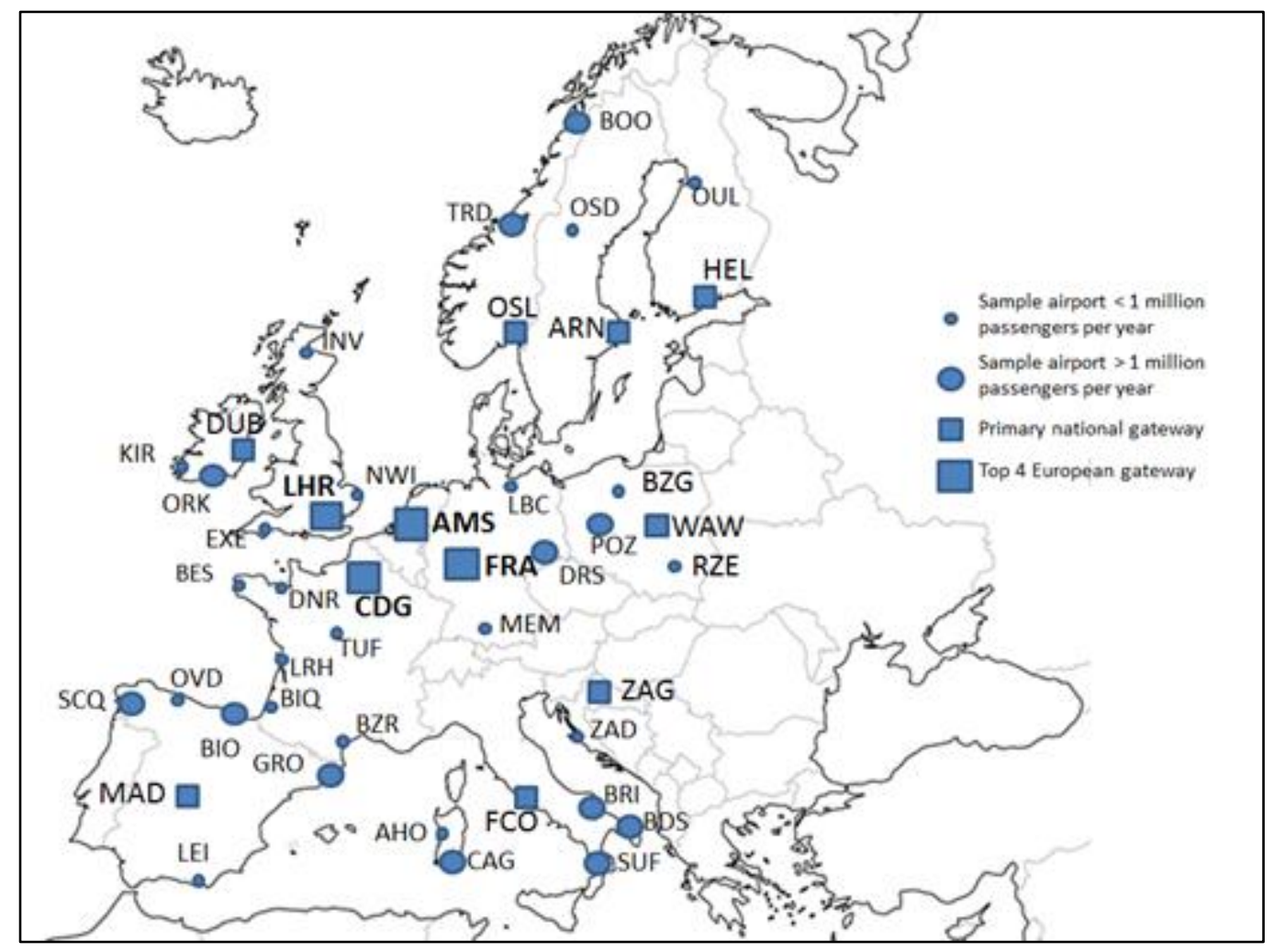

Figure 1: Map of airports

\subsection{Shortest path length}

We use the shortest path length (SPL) measure of airport connectivity. Although it does not incorporate measures of connection time and total flight time, we considered that it was the most adequate measure because of its simplicity and transparency. Furthermore, as argued by most of the literature on air transport in remoter regions (e.g., Williams and Bråthen, 2010), the first and essential priority for these communities is the capacity to maintain and secure air services and travel options. Transfer times and the quality of connections could be considered as secondarylevel priorities. In this regard, SPL has been used in the past to measure the connectivity of small airports (Malighetti et al., 2008; Paleari et al., 2010; Redondi et al., 2013) and the hub performance of US airlines after deregulation (Shaw, 1993; Shaw and Ivy, 1994). SPL counts the number of steps (i.e., flights or flight legs) between an origin and a destination airport on the shortest path possible. There are likely to be multiple connections between a given airport pair. SPL takes a value of 1 when there is a non-stop direct connection between the airport pair. However, in a given network, many destinations can only be accessed by making two or even three-step connections where transfers are required at intermediate airports.

For any single airport within a given network, we can obtain an average shortest path length (ASPL) by measuring the SPL of all possible origin-destination pairs in the network departing from an airport. The average of these SPL values results in the average shortest path length, or ASPL. The ASPL for a given airport $i$ within a network that contains $j$ destination airports is as follows: 
$A S P L_{i}=\frac{n}{n-1} \sum_{j=1}^{n} S P L_{i j}$

The lower the ASPL, the higher the connectivity of the airport within a given network. Nevertheless, for the purpose of clarity, we transform the above equation to create a connectivity values that are constrained between between 0 and 1 . Results close to 1 mean better airport connectivity; inversely, results close to 0 indicate a poor airport connectivity. The ASPLCV for a given airport $i$ is as follows:

$A S P L C V_{i}=\frac{1}{A S P L_{i}}$

We calculate intra-European airport connectivity and distinguish between two types of network: alliance and non-alliance. Alliance connections are those flight paths which are flown within a single FSNC airline or alliance network. Non-alliance connections, on the other hand, are flight itineraries offered by independent airlines, LCCS and connections between airlines that are not aligned by any formal co-operation agreement or alliance.

\subsection{Maximum Lapsed Destination Time}

In addition to measuring intra-European connectivity at small airports, we also consider the quality of schedules offered for day-return trips, as these connections maintain accessibility between smaller communities and capital cities thereby sustaining local population levels and continued economic development. Pagliari (2003), in an analysis of the impact of airline franchising in the Scottish Highlands and Islands, used Maximum Lapsed Destination Time (MLDT) to measure the extent to which passengers were able to complete day-return journeys within a single city-pair market. MLDT is defined as the difference between the earliest arrival time and the latest return departure possible. A high MLDT would allow passengers to achieve day-return travel to their destination, obviating the need for over-night accommodation; this is especially important and relevant to business travellers and others travelling for other personal reasons, such as for instance medical visits, that might not have access to flexible tickets. We seek to investigate, therefore, the extent to which MLDT changes as a consequence of LCC entry on small regional airport-hub city-pair markets.

We have identified 18 city-pairs that fulfil these characteristics in our sample. For each city-pair there are two MLDT measurements; one for travel from the small regional airport to the hub and another from the hub to the small regional airport. Monday in the second week of September is used as a reference day. Since the year of LCC entry differs from route to route, the reference years have been adjusted for each city-pair. For example, the route from Kerry to Dublin, formerly served by Aer Arann, was taken over by Ryanair in 2008. But the carrier exited the market again after 2010. Consequently, the reference years are 2007 for the pre-low-cost period and 2010 for post-entry.

Also, it is important to note that only flights from a single airline are paired. For example, on the route from Kerry to Dublin, only return connections with either Aer Arann or Ryanair are classified as valid. To fly to Dublin with Ryanair in the morning and returning in the evening on Aer Arann would have been classed as invalid connection and therefore not considered in the analysis. 
4.1 Overall connectivity at small airports 2002-2012

Figure 2 shows average alliance and non-alliance European network connectivity values recorded across the sample airports for the period 2002-2012. Alliance connectivity rises initially after 2002 before experiencing a modest decline between 2005 and 2008, followed by a small recovery to 2012. The decline in the 2005-2008 period could be explained, on the one hand, by increasing penetration of LCCS in less dense markets and, on the other hand, by the effects of the 2008 financial crisis. A partial recovery in the post-2008 period allows FSNCs to achieve connectivity values comparable to 2004-2005 levels, although offering services from slightly fewer airports (e.g. Inverness, Cork lose Alliance connectivity). In this regard, our results support the findings of SuauSanchez et al. (2015) who observe rising inequality between smaller airports during the period 19902009. In contrast, non-alliance connectivity rises sharply between 2002 and 2008 followed by a period where it remains largely stable. Modest increases in the post-2008 period could be due to growth limits inherent within the LCC model and associated network density problems (de Wit and Zuidberg, 2012). Nevertheless, we can conclude that from 2006, non-alliance connectivity provided by LCCs is of a higher quality (fewer average intermediate stops) when compared to that offered by FSNCs.

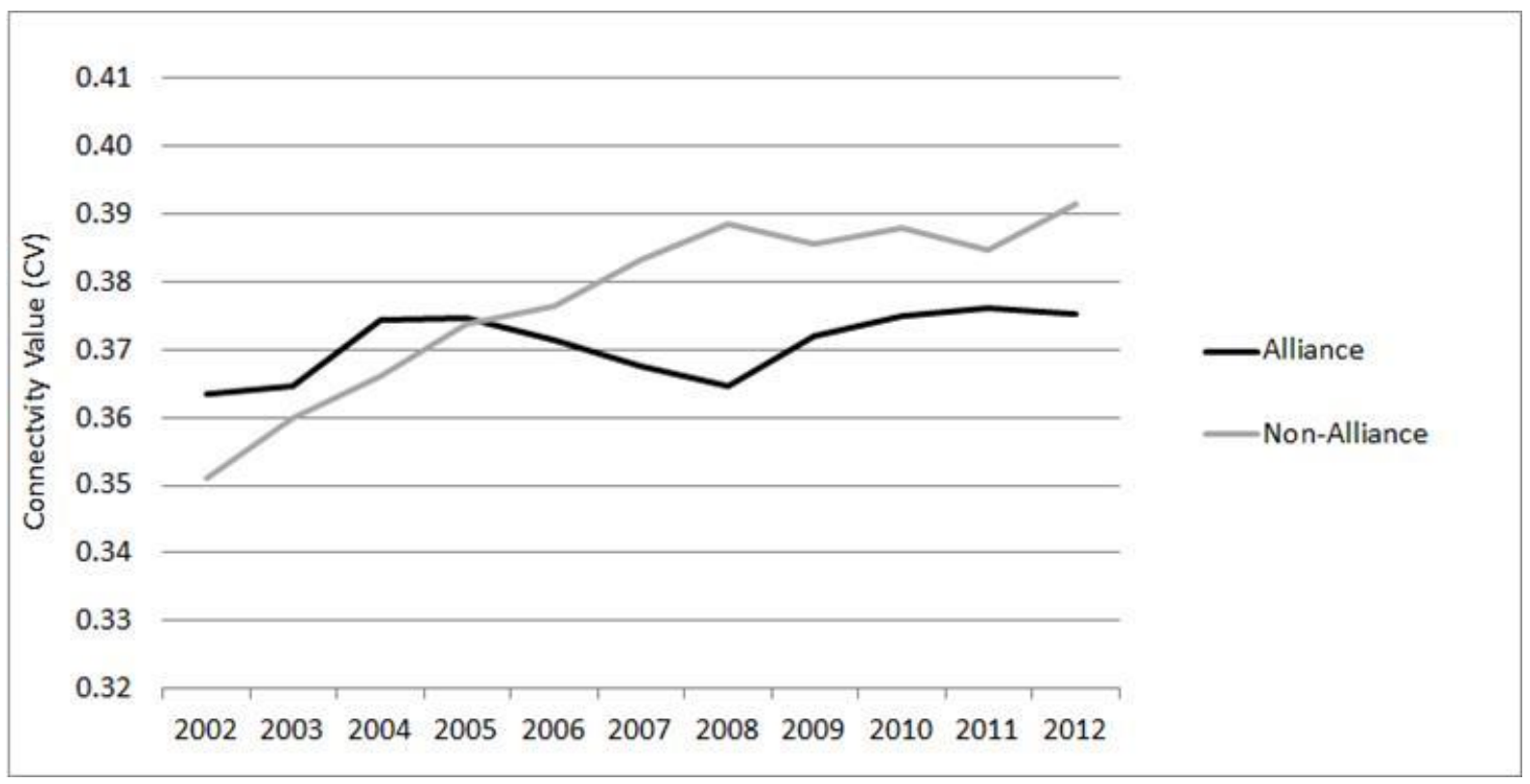

Figure 2: Europe-wide connectivity values (CV) for 2002-2012

In order to gain further insights into market developments at the airport level and the key airlines driving change, we also report alliance and non-alliance connectivity by airport type in Figures 3 and 4. In Figure 3, patterns are relatively minor. However, we can observe that connectivity values for Type 1 and 3 airports remain relatively stable throughout the period. For Type 1 airports (experienced LCC entry on key routes served by FSNCs) connectivity values increases to 2005 before falling to 2008 and then recovering to achieve ratios very close to both Type 2 and 3 airports. Higher 
growth is achieved, on average, by Type 2 airports where LCCs entered non-hub markets. Hence, the level of competition faced by the FSNC on a route can have a negative effect on the quality of connectivity that is offered; for example, in terms of service frequency and the ability to offer connections to onward destinations beyond the hub. In this regard, LCC entry in a city-pair market already served by an FSNC hub feeder service (either on the same route or on a route from the same regional airport to a secondary airport in the same airport system as the hub) can have detrimental effects if the goal of the region is to maintain onward connectivity via an alliance hub.

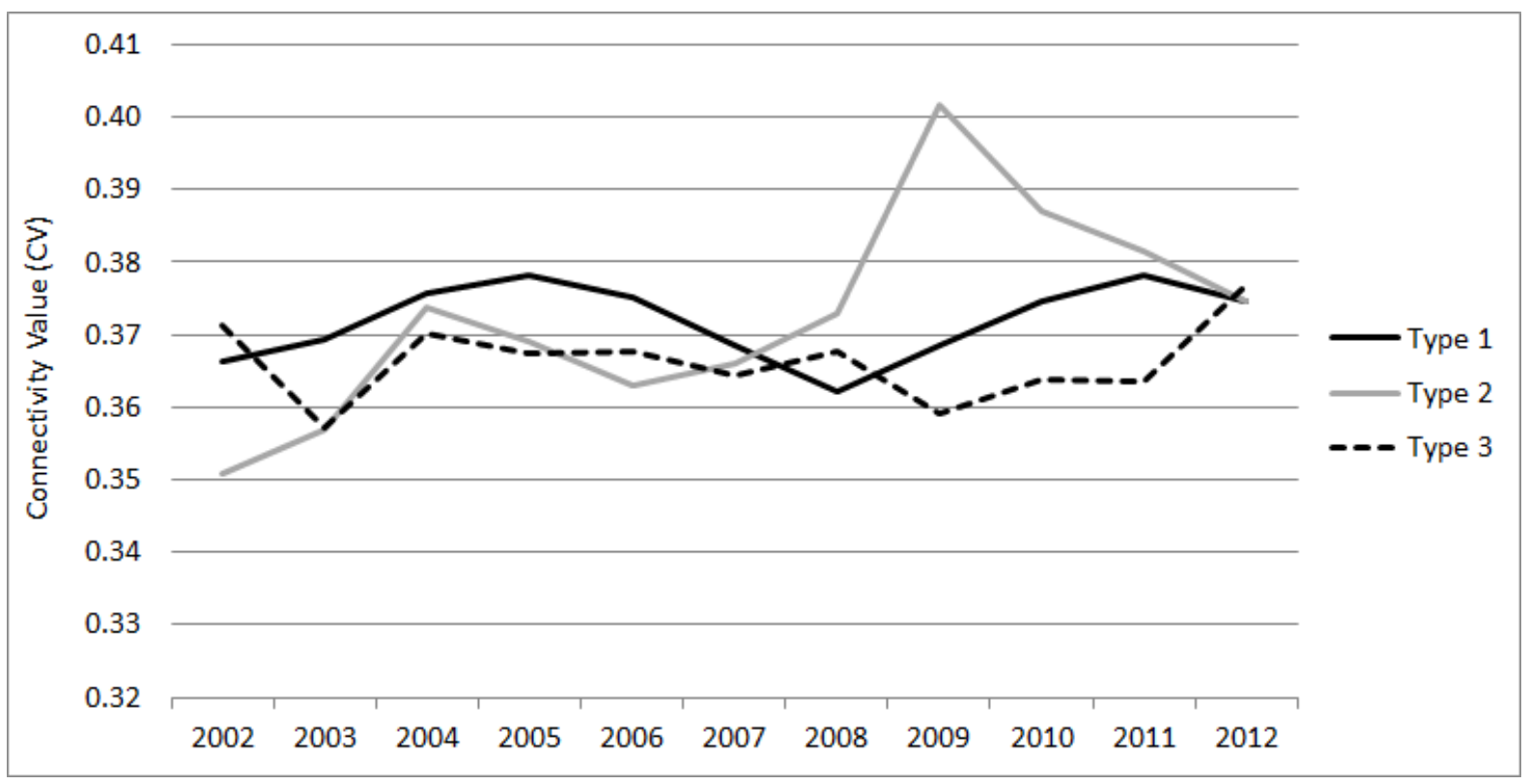

Figure 3: European FSNC alliance average Connectivity Value by airport type 2002-2012.

With regard to non-alliance connectivity (Figure 4), both Type 1 and Type 2 airports sustained steady improvements in connectivity values between 2002 and 2007-2008. Thereafter, connectivity values do change significantly; Type 1 airports show higher levels of connectivity, probably because many LCCS have extensive operations in FSNC hubs, which can exponentially increase the number of potential connections between LCC flights. A substantial connectivity increase of nearly $30 \%$ can be observed from 2002 to 2012 at Type 2 airports; equivalent to a change in ASPL from 3.4 to 2.6. This represents, in passenger itinerary terms, an average saving of one flight to reach any other airport in the network. Hence, non-alliance connectivity growth was concentrated at airports offering more connections on thinner routes to non-hub airports. This observation was also reported by de Wit and Zuidberg (2012) who claim that Ryanair was the only effective initiator of route development between 2001 and 2010. Their strategy focussed on serving thin routes due to saturation and limitations to further growth in denser markets. 


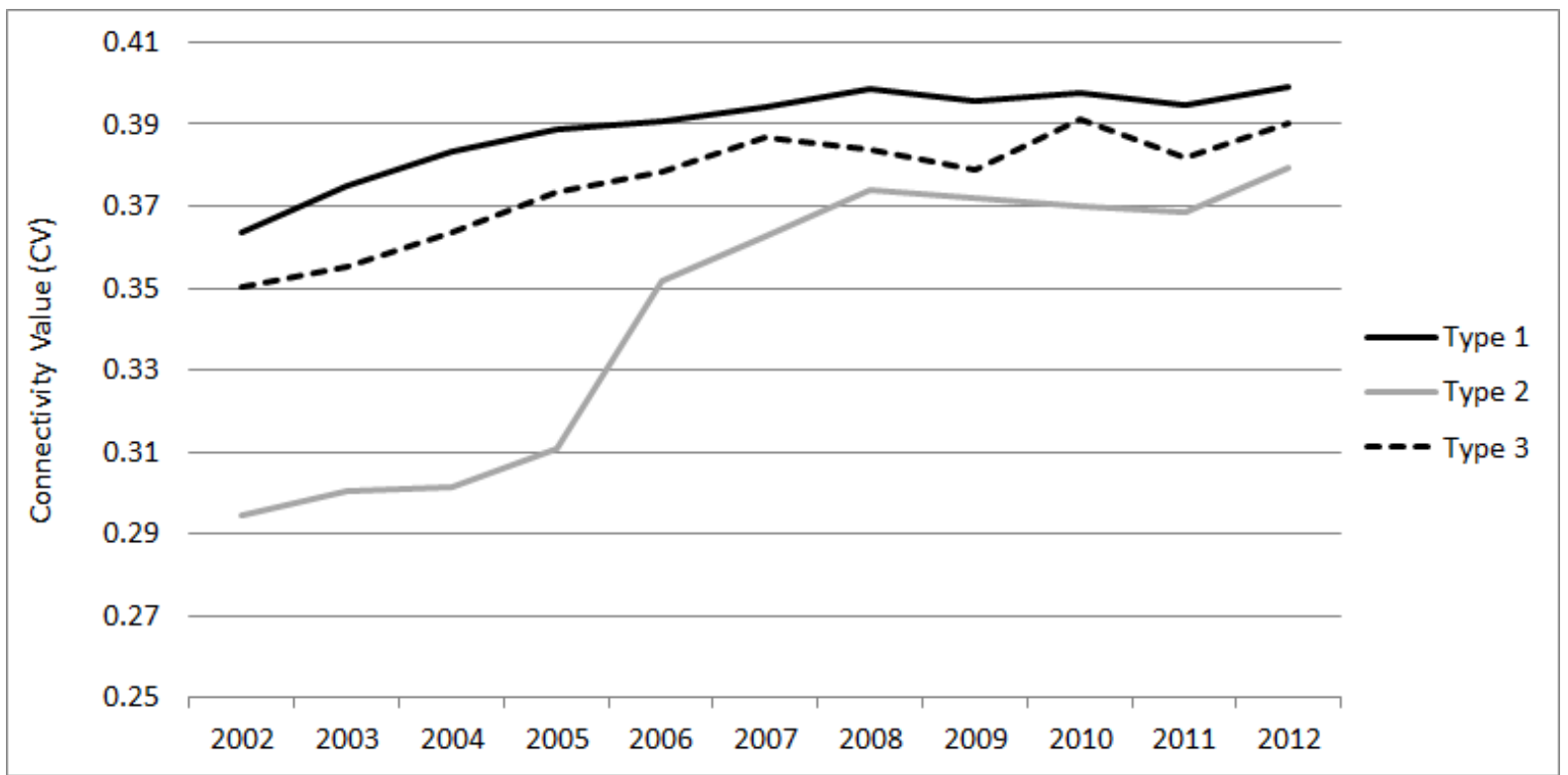

Figure 4: European non-alliance average Connectivity Value by airport type 2002-2012

Overall non-alliance connectivity values increased during the period of analysis. This development occurred in parallel with increasing LCC market penetration of the intra-European market (Dobruszkes, 2013). So, whilst LCCs do not operate formal hub-and-spoke systems, the volume of point-to-point flights is such that a wide range of connection possibilities are available to passengers. For small airports, a regular direct service to an LCC base can naturally lead to a significant increase in European connectivity.

\subsection{Individual small airport connectivity}

Table 2 illustrates the impact on alliance and non-alliance connectivity of LCC entry on Type 1 and 2 airports. Connectivity values are reported before and after LCC entry (latest year).

\section{Alliance connectivity}

The effects of LCC entry on alliance connectivity are quite diverse, ranging from the establishment of FSNC flights at Memmingen $(+100 \%)$ to complete withdrawal of services at Cork, La Rochelle, Inverness and Girona (-100\%). Other airports experience relatively modest changes in alliance connectivity. Therefore, significant FSNC reaction to LCC entry only occurs in a small number of cases. In these cases, the implications of connectivity loss experienced by both La Rochelle and Inverness appear more significant compared to Cork and Girona. In the former case, shortest drive distances to their international gateways. Paris Charles de Gaulle $(493 \mathrm{~km})$ and London Heathrow $(556 \mathrm{~km})$, are much greater than in the latter; Dublin $(266 \mathrm{~km})$ and Barcelona $(105 \mathrm{~km})$. 
Table 2: Alliance and Non-alliance Connectivity Values (CV) before and after LCC entry (Type 1 and Type 2 airports).

\begin{tabular}{|c|c|c|c|c|c|c|c|c|}
\hline \multirow[b]{2}{*}{ Airport } & \multirow[b]{2}{*}{ Type } & \multicolumn{2}{|c|}{ Base Year CV } & \multicolumn{2}{|c|}{ Low-cost Year CV } & \multicolumn{2}{|l|}{ \% Change } & \multirow{2}{*}{$\begin{array}{l}\text { Low-cost } \\
\text { Airline }\end{array}$} \\
\hline & & Alliance & $\begin{array}{l}\text { Non- } \\
\text { alliance }\end{array}$ & Alliance & $\begin{array}{l}\text { Non- } \\
\text { alliance }\end{array}$ & Alliance & $\begin{array}{l}\text { Non- } \\
\text { alliance }\end{array}$ & \\
\hline
\end{tabular}

\section{Type 1}

$\begin{array}{lllllllll}\text { Girona } & 1 & 0.347 & 0.426 & - & 0.427 & -100 \% & 0 \% & \text { Ryanair } \\ \text { Inverness } & 1 & 0.382 & 0.382 & - & 0.388 & -100 \% & 2 \% & \text { Easyjet } \\ \text { Cork } & 1 & 0.330 & 0.416 & - & 0.432 & -100 \% & 4 \% & \text { Ryanair } \\ \text { Biarritz } & 1 & 0.423 & 0.400 & 0.362 & 0.401 & -14 \% & 0 \% & \text { Easyjet } \\ \text { Santiago de Comp } & 1 & 0.383 & 0.380 & 0.350 & 0.401 & -9 \% & 6 \% & \text { Vueling, } \\ \text { Cagliari } & 1 & 0.426 & 0.421 & 0.396 & 0.407 & -7 \% & -3 \% & \text { Ryanair } \\ \text { Asturias } & 1 & 0.349 & 0.388 & 0.337 & 0.394 & -3 \% & 1 \% & \text { Vueling, } \\ \text { Bilbao } & 1 & 0.425 & 0.434 & 0.419 & 0.445 & -1 \% & 3 \% & \text { Vueling, } \\ \text { Brest } & 1 & 0.423 & 0.390 & 0.421 & 0.384 & 0 \% & -2 \% & \text { Easyjet } \\ \text { Alghero* } & 1 & - & 0.384 & - & 0.403 & - & 5 \% & \text { Easyjet, } \\ \text { Kerry* } & 1 & - & 0.367 & - & 0.370 & - & 1 \% & \text { Ryanair } \\ \text { Leipzig } & 1 & 0.371 & 0.410 & 0.381 & 0.408 & 3 \% & -1 \% & \text { Ryanair } \\ \text { Oulu } & 1 & 0.347 & 0.352 & 0.357 & 0.363 & 3 \% & 3 \% & \text { Norwegian } \\ \text { Bari } & 1 & 0.368 & 0.413 & 0.389 & 0.415 & 6 \% & 0 \% & \text { Easyjet, } \\ \text { Bodo } & 1 & 0.325 & 0.318 & 0.346 & 0.342 & 7 \% & 7 \% & \text { Norwegian } \\ \text { Trondheim } & 1 & 0.357 & 0.346 & 0.383 & 0.412 & 7 \% & 19 \% & \text { Norwegian } \\ \text { Brindisi } & 1 & 0.344 & 0.385 & 0.371 & 0.392 & 8 \% & 2 \% & \text { Ryanair } \\ & & & & & & & & \\ \text { Type 2 } & & & & & & & & \\ \text { La Rochelle } & 2 & 0.324 & 0.328 & - & 0.378 & -100 \% & 15 \% & \text { Ryanair } \\ \text { Poznan } & 2 & 0.431 & 0.397 & 0.426 & 0.428 & -1 \% & 8 \% & \text { Wizz Air, } \\ \text { Bydgoszcz } & 2 & 0.347 & 0.330 & 0.346 & 0.362 & 0 \% & 10 \% & \text { Ryanair } \\ \text { Beziers } & 2 & - & 0.315 & - & 0.361 & - & 14 \% & \text { Ryanair } \\ \text { Dinard } & 2 & - & 0.315 & - & 0.334 & - & 6 \% & \text { Ryanair } \\ \text { Luebeck } & 2 & - & 0.309 & - & 0.367 & - & 19 \% & \text { Wizz Air, } \\ \text { Tours } & 2 & - & 0.327 & - & 0.372 & - & 14 \% & \text { Ryanair } \\ \text { Lamezia } & 2 & 0.373 & 0.416 & 0.376 & 0.409 & 1 \% & \text { Ryanair } \\ \text { Rzeszow } & 2 & 0.346 & 0.338 & 0.405 & 0.391 & 17 \% & \text { Wizz Air, } \\ \text { Memmingen } & 2 & - & 0.291 & 0.317 & 0.395 & 100 \% & 36 \% & \text { Easyjet, }\end{array}$

*Note: Although Alghero and Kerry did not have alliance connectivity, they are still considered to be part of Type 1 because a network carrier was providing connectivity.

When all FSNCs exit an airport, all alliance connectivity is lost. Yet, in those airports that experienced a complete loss of all alliance connectivity, the FSNCs were, in most cases, offering only one connection (e.g., Girona-Madrid, Inverness-London). But when FSNCs have more substantial operations at an airport and they make adjustments to their networks by either expanding or reducing the number of destinations served, the impact of these changes does not manifest itself in significant changes to connectivity. Modest changes may be explained by an FSNC's reluctance to withdraw important feeder services. Usually, FSNCs operate to their main hub or other important airports where the available number of onward connections can be extensive4. Therefore, when the FSNC offers flights to a diverse range of airports, removing one route may not substantially alter the

\footnotetext{
${ }^{4}$ Note that our analysis is based on the shortest path length, which cannot capture the impact of changes in frequency and scheduling.
} 
number of flight steps needed to reach a final destination depending on the particular configuration and scope of its network.

Comparing results by airport type, we observe that for Type 1 airports, average alliance connectivity declines by $11 \%$ in contrast to an average increase of $2 \%$ for Type 2 . For Type 2 airports changes in alliance connectivity are independent of LCC entry as this occurs only on non-key routes. The modest $2 \%$ increase may be explained by improved network performance and increased connection possibilities at the destination airport. However, LCC entry on key routes to hubs can have an adverse effect on connectivity within an alliance network, if the incumbent FSNC reacts by withdrawing services. Note that some airports did not report any change in alliance connectivity as they may have had no alliance connection in the years analysed; this is true for many Type 2 airports.

\section{Non-alliance connectivity}

All airports, with the exception of the more remote Cagliari, Brest, Lamezia and Leipzig, experience an improvement in non-alliance connectivity following LCC entry. Also those airports that lost alliance connectivity were compensated by new LCC services which increased non-alliance connectivity. La Rochelle, for example, lost its Air France link to Paris, but benefited from a 15\% increase in non-alliance connectivity after a connection was re-established by Ryanair. However, when non-alliance replaces alliance connectivity there can be adverse effects on both the quality and value of destinations that are served. For example, in 2012, Air France served an extensive range of primary airports in Europe. This is in contrast to Ryanair who tended to operate to secondary and small regional airports. There are only a few cases where both alliance and non-alliance connectivity have expanded simultaneously. At Rzeszow, for example, passengers benefited from LCC entry and improved alliance connectivity over time. Ryanair introduced a regular service to Dublin, which offers self-connecting opportunities to a wide range of destinations. Luebeck is a similar case, where services were introduced to Dublin as well as to London Stansted.

Different connectivity effects were also observed depending on whether Ryanair or Easyjet were the first LCCs to serve an airport. Those airports initially served by Ryanair experienced a higher increase in non-alliance connectivity compared to those initially served by other LCCs, such as Easyjet. Indeed, average connectivity decreases by $15 \%$ at those airports that first experienced Easyjet entry in contrast to reduction of $9 \%$ with regard to Ryanair cases. This demonstrates an important difference in the comparative effects of Ryanair and other LCCS on FSCN operations at small airports. Ryanair's effect was less apparent as they tended to serve low-density monopolistic markets. Easyjet, on the other hand, preferred to operate to larger primary airports in direct proximity to incumbent FSNC services, raising the risk of route displacement considerably. This displacement phenomenon occurred at Biarritz where Air France terminated feeder flights to Paris Charles de Gaulle shortly after Easyjet's entry into the market. For the community of Biarritz, one of the most peripheral cities in Mainland France, relative to Paris, the effect is more significant especially when considering the implications with regard to accessibility to world markets. 
Non-alliance connectivity increased at Type 2 and Type 1 airports, on average, by $13 \%$ and 3\% respectively. Non-alliance connectivity growth occurs at Type 2 airports usually following the introduction of direct flights to new destinations, thereby lowering average shortest path length in the network. For example, the less remote Poznan airport was served by direct links to Frankfurt, Copenhagen, Munich and Warsaw. Following the launch of flights to new destinations such as Barcelona and Dublin by both Ryanair and Wizzair, this had the effect of increasing non-alliance connectivity because these airports, in themselves, were able to offer additional connectivity to onward destinations. Type 1 airports could not deliver substantial increases in non-alliance connectivity because although the serving LCC's entry on the key route could provide onward connectivity options via the hub, it could not supply additional direct flights.

Overall, we can conclude that the introduction of LCC services on routes to hub airports can impact negatively on alliance connectivity, which is only partly replaced by non-alliance links, which require passengers to self-transfer between flights. The quality of these schedules can be inferior in many respects to a seamless FSNC itinerary which can offer guaranteed and insured connections to onward destinations. In general the more remote airports suffer major connectivity loses compared to the less remote airports.

\subsection{Maximum Lapsed Destination Time (MLTD)}

MLDT measures the extent to which passengers are able to complete day-return journeys within a single city-pair market. According to Table 3 below, average MLDT declined by $6 \%$ across our sample of city-pairs following LCC entry. In absolute terms, average MLDT declined from 11 hours 52 minutes (11:52) to 11 hours 10 minutes (11:10). However, significant differences were reported depending on whether travel itineraries were small airport outbound or inbound.5 Average MLDT on outbound routes prior to LCC entry was 13:26 compared to an inbound average of 10:07. This disparity is most probably explained by airlines timetabling flights to meet directional demand flows within city-pairs. Often in these markets, there is significantly higher early morning demand on outbound flights compared to inbound services, which means the requirement to night-stop aircraft at small airports. In these cases, small airport markets enjoy early morning access to the main airports and a potentially higher MLDT.

On five out of the 16 city-pairs, the FSNC reacted by withdrawing services, leaving the LCC entrant(s) as the only operator(s). We observed disparities in the extent to which MLDT was affected by LCC entry across these cases. On the Cork-Dublin city-pair, for example, Ryanair's displacement of Aer Arran led to a significant decrease in MLDT in both travel directions. In contrast, Ryanair's entry into the Girona-Madrid market improved MLDT on both the outbound and inbound directions by $15 \%$ and $25 \%$ respectively. This disparity can be explained by how Ryanair used both airports.

\footnotetext{
${ }^{5}$ Small airport outbound is defined as small airport to main airport and inbound as main airport to small airport.
} 
Table 3: $\quad$ Selected city-pair MLDT (hours:mins) pre-LCC entry and post LCC entry

\begin{tabular}{|c|c|c|c|c|c|}
\hline & Pre LCC & Post LCC & $\begin{array}{l}\text { Highest MLTD Post } \\
\text { LCC entry }\end{array}$ & LCC entrant & $\%$ change \\
\hline \multicolumn{6}{|l|}{ France } \\
\hline Biarritz - Paris & $13: 15$ & $11: 50$ & FSC & \multirow[t]{2}{*}{ Easyjet } & $-11 \%$ \\
\hline Paris - Biarritz & $11: 45$ & $11: 55$ & LCC & & $+1 \%$ \\
\hline \multicolumn{6}{|l|}{ Ireland } \\
\hline Cork-Dublin & $14: 55$ & $10: 05$ & LCC* & \multirow[t]{2}{*}{ Ryanair } & $-32 \%$ \\
\hline Dublin - Cork & $13: 55$ & $\mathrm{n} / \mathrm{a}$ & LCC* & & $-100 \%$ \\
\hline Kerry - Dublin & $15: 10$ & $14: 10$ & FSC & \multirow[t]{2}{*}{ Ryanair } & $-7 \%$ \\
\hline Dublin - Kerry & $10: 15$ & $11: 40$ & FSC & & $14 \%$ \\
\hline \multicolumn{6}{|l|}{ Italy } \\
\hline Alghero-Rome & $14: 05$ & $13: 20$ & FCC & \multirow{2}{*}{ Ryanair } & $-5 \%$ \\
\hline Rome - Alghero & $11: 05$ & $08: 55$ & FCC & & $-20 \%$ \\
\hline Alghero-Milan & $14: 10$ & $13: 55$ & FCC & \multirow{2}{*}{ Ryanair } & $-2 \%$ \\
\hline Milan - Alghero & $12: 00$ & 09:30 & FCC & & $-21 \%$ \\
\hline Brindisi - Rome & $13: 15$ & $13: 30$ & FSC & \multirow{2}{*}{ Ryanair } & $+2 \%$ \\
\hline Rome - Brindisi & $07: 40$ & $08: 50$ & FSC & & $+15 \%$ \\
\hline Bari-Rome & $13: 50$ & $13: 40$ & FSC & \multirow[t]{2}{*}{ Ryanair } & $-1 \%$ \\
\hline Rome - Bari & 09:05 & $12: 30$ & LCC & & $+38 \%$ \\
\hline Cagliari-Rome & $13: 45$ & $13: 55$ & FSC & \multirow[t]{2}{*}{ Ryanair } & $1 \%$ \\
\hline Rome - Cagliari & $10: 05$ & 09:40 & LCC & & $-4 \%$ \\
\hline \multicolumn{6}{|l|}{ Spain } \\
\hline Asturias - Barcelona & $13: 00$ & $12: 10$ & LCC* (Vueling) & \multirow{2}{*}{ Vueling \& Ryanair } & $-6 \%$ \\
\hline Barcelona - Asturias & 08:50 & $12: 50$ & LCC* (Ryanair) & & $45 \%$ \\
\hline Bilbao - Madrid & $13: 25$ & $13: 20$ & FSC & \multirow{2}{*}{ Easyjet } & $-1 \%$ \\
\hline Madrid - Bilbao & $13: 35$ & $13: 45$ & FSC & & $+1 \%$ \\
\hline Bilbao - Barcelona & $14: 20$ & $14: 15$ & LCC* & \multirow{2}{*}{ Vueling \& Ryanair } & $-1 \%$ \\
\hline Barcelona - Bilbao & $12: 40$ & $12: 05$ & LCC* & & $-5 \%$ \\
\hline Girona - Madrid & 09:10 & $11: 25$ & LCC* & \multirow[t]{2}{*}{ Ryanair } & $+25 \%$ \\
\hline Madrid - Girona & 09:20 & $11: 00$ & LCC* & & $+18 \%$ \\
\hline Almeria - Madrid & $11: 55$ & $13: 00$ & FSC & \multirow[t]{2}{*}{ Ryanair } & $+9 \%$ \\
\hline Madrid - Almeria & $10: 05$ & $07: 40$ & FSC & & $-24 \%$ \\
\hline Santiago d.C. - Madrid & $15: 55$ & $14: 45$ & FSC & \multirow[t]{2}{*}{ Ryanair } & $-7 \%$ \\
\hline Madrid - Santiago d.C. & $11: 30$ & $14: 45$ & LCC & & $28 \%$ \\
\hline Santiago d.C. - Barcelona & $13: 40$ & 09:10 & LCC* (Vueling) & \multirow{2}{*}{ Vueling \& Ryanair } & $-33 \%$ \\
\hline Barcelona - Santiago d.C. & $11: 15$ & $13: 05$ & LCC* (Ryanair) & & $16 \%$ \\
\hline \multicolumn{6}{|l|}{ United Kingdom } \\
\hline Inverness - London Gatwick & $10: 55$ & $10: 30$ & FSC & Easyjet & $-4 \%$ \\
\hline London Gatwick - Inverness & $05: 45$ & 06:05 & FSC & Easyjet & $+6 \%$ \\
\hline
\end{tabular}


Firstly, Girona was a Ryanair base allowing early departures, whilst Cork functioned as out-station. Secondly, Ryanair was competing with Spanair's Girona-Madrid services, which incentivised the LCC to offer competitive departure times. Thirdly, the driving distance between Cork and Dublin is $259 \mathrm{~km}$, in contrast to $688 \mathrm{~km}$ between Girona and Madrid. So, in the former case, driving would be a more compelling alternative travel proposition for passengers. Indeed, in most of the other routes where the LCC is utilising the smaller airport as an out-station, the effect of market entry was manifested in higher MLDT on the inbound leg and a reduction on the outbound (e.g., AsturiasBarcelona, Santiago de Compostela-Barcelona, Biarritz-Paris) favouring populations resident in the larger urban centres. In the Barcelona markets, the drive distances from Santiago de Compostela and Asturias are quite significant; $1,105 \mathrm{~km}$ and $896 \mathrm{~km}$ respectively.

However, there are instances where the incumbent FSNC maintained its operations in the face of LCC entry (11 out of the 16 city-pairs). Again, the results indicate divergent effects. In the Italian cases, for example, the FSNC continued the service by offering an improved MLDT compared to that offered by the LCC new entrant, but at a lower level compared to what was supplied prior to market entry. In other words, passengers benefited from having a choice of carrier but this was at expense of lower MLDT. In other markets, the changes in MLDT were quite insignificant. In these cases the FSNC incumbent maintained its schedule, with the competing LCC offering just single daily frequencies and/or off-peak services. We observed this in relation to both Bilbao-Barcelona and Inverness-London Gatwick city-pairs. In the latter case, Easyjet entered the market offering a single rotation in direct competition with three daily services offered by British Airways.

Whilst the effect on most of the markets has been negative, the loss in MLDT is only significant in a few cases (i.e., Santiago de Compostela, Cork and Biarritz). In most markets, regional residents are still able to complete viable day return trips to key metropolitan cities despite the impact of LCC entry on a route served by a FSNC. Indeed, it is also important to highlight the fact that in those citypairs where the LCC is sole operator, MLDT times do not allow regional residents to complete a day return (i.e., Cork-Dublin, Asturias-Barcelona, Santiago-Barcelona).

\section{Discussion and conclusions}

Our analysis has focused on two dimensions of air service supply; we have evaluated the evolution of alliance and non-alliance connectivity and Maximum Lapsed Destination Time (MLDT) after LCC entry. We agree with Mallighetti et al. (2008), who argue that there is significant scope for exploiting non-alliance connectivity in the intra-European market. Through focusing on smaller airports, we were able to assess the effects of LCC entry on connectivity at the weakest and most vulnerable segment of the airport hierarchy. In this regard, our findings demonstrate an uneven distribution of connectivity in both quantity and quality dimensions. However, we also recognise and accept that there are limitations inherent in the SPL approach which restricts the analysis to measuring the impact on connections and not at a more granular level of supply (e.g. frequency and scheduling).

From 2006 onwards, we found that non-alliance connectivity provided by LCCs is of higher quality (i.e., less average intermediate stops) than the alliance connectivity offered by FSNCs. Furthermore, 
LCC entry at the route level had a negative effect on the quality of the connectivity offered by FSNCs to hub airports; also, the loss of alliance connectivity is only partly replaced by non-alliance connections requiring passengers to self-transfer. Although pricing effects are outside of the scope of this paper, it is worth noting that lower connectivity quality may be compensated by lower fares (Windle and Dresner, 1999; Alderighi et al., 2012; Salanti et al., 2012). We also found that nonalliance connectivity growth was more apparent at those airports where LCCs offered additional connections on thinner routes to non-hub destinations. Indeed, the results observed depended on whether Ryanair or Easyjet. Ryanair's effect was less apparent as they tended to serve low-density monopolistic markets. EasyJet, on the other hand, preferred to operate to larger primary airports in direct proximity to incumbent FSNC services, raising the risk of route displacement considerably. This is consistent with the findings of Fageda and Flores-Fillol (2012) who observed that European LCCs dominate routes with a lower number of supplied seats and in airports located at a greater distance from city centres. However, the remoter airports did not experience any improvement in nonalliance connectivity, which points to a polarisation of the lower end of airport hierarchy (see, also, Suau-Sanchez et al., 2016a).

We use a relatively limited sample of 33 airports. This sample includes airports that have diverse geographies and market characteristics. To recognise and incorporate this diversity and to test the sensitivity of our results, we calculate connectivity values for sub-samples of airports based on distance (degree of remoteness) and size (volume of passenger traffic).

The majority of our airports are located within $200 \mathrm{~km}$ driving distance from an alternate facility. However, it could be that these alternate airports do not necessarily offer comparable or effective levels of connectivity. An alternative approach is to measure the degree of remoteness as driving distance from the nearest airport that offers direct flights by any one of the four major European FSNCs via their respective hubs 6 . Using this criterion, 14 and 18 airports were classified as more remote and less remote respectively (see Table 1 ).

Before 2008, less remote airports, on average, achieved higher levels of alliance connectivity compared to the other sample. However, after 2008, the order is inverted with the remoter airports achieving marginally higher connectivity. However, by 2012, connectivity values for both samples converge around the all airport average.

\footnotetext{
${ }^{6}$ Defined as services operated by British Airways, KLM, Air France and Lufthansa and their partners to their respective primary hub airports at London Heathrow, Amsterdam, Paris Charles de Gaulle and Frankfurt..
} 


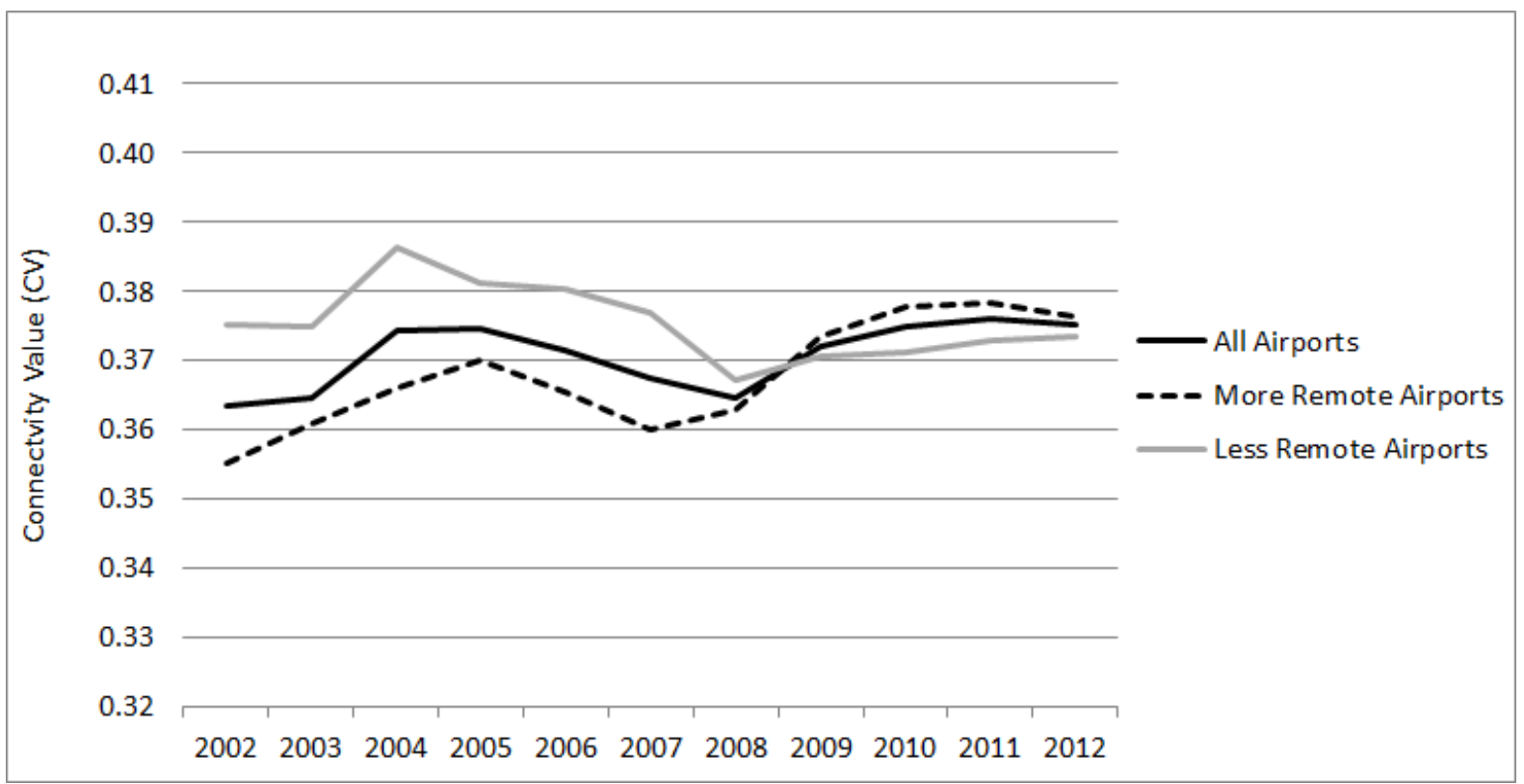

Figure 5: Average European Alliance Connectivity Values by Type of Airport (degree of remoteness) 2002-2012

Similarly with non-alliance connectivity (Figure 5), we do not see substantial divergence from the total airport average. Indeed the differences narrow quite considerably after 2006

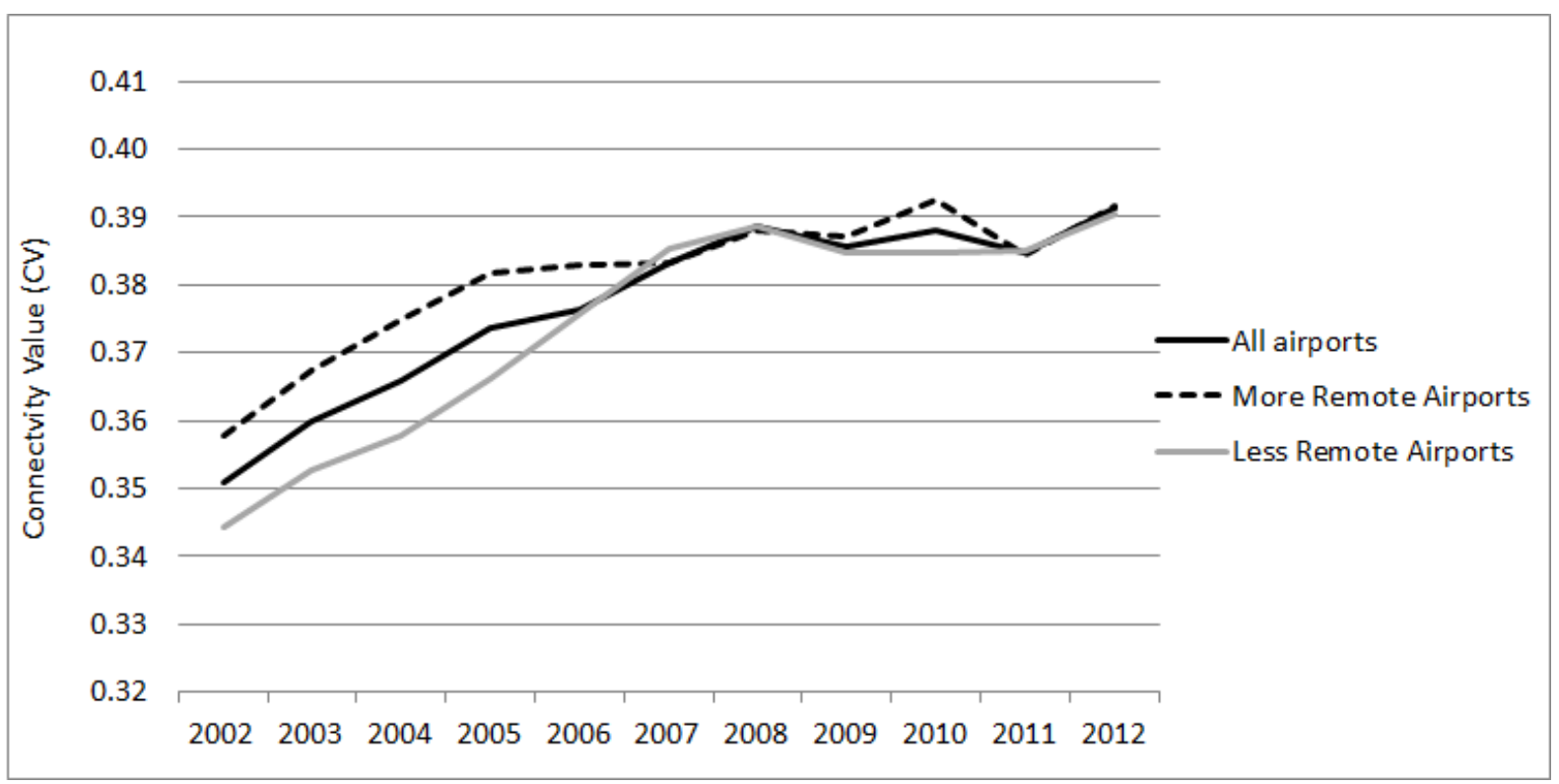

Figure 6: Average European Non-Alliance Connectivity Values by Type of Airport (degree of remoteness) 2002-2012.

In terms of volume of traffic, we consider two sub-samples of airports; those handling less than 1 million passengers per year (small airports) and those handling greater than 1 million passengers per year (large airports). 13 airports were classed as large and 19 as small. 
Figure 7 contrasts alliance connectivity values for large and small airports and shows that up to 2005, the ratios were virtually identical. After 2006, the values diverge with the position of smaller airports weakening and then recovering after 2008 before remaining relatively stable to 2012. For larger airports, connectivity values improves throughout the period, particularly after 2009 . This may be a reflection of alliance capacity retrenchment at smaller-sized airports where there are weaker underlying market conditions. The weakening in connectivity commences in 2004 and continues to 2008, before recovering to 2012. Inverness and Biarritz are particularly affected by LCC displacement during this period as well as Oulu and Oestersund.

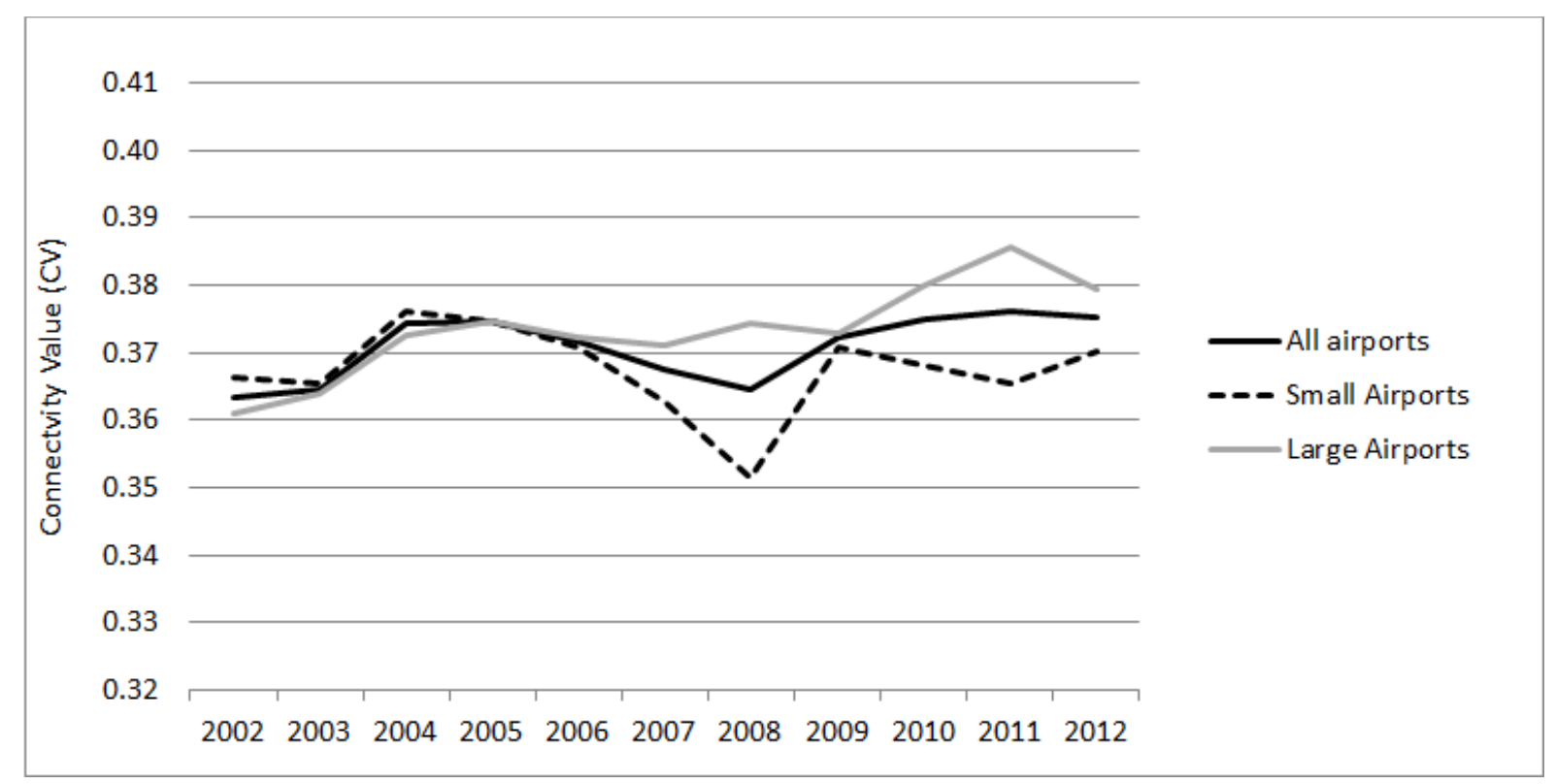

Figure 7: Average European Alliance Connectivity Values by Size of Airport 2002-2012

We can observe similar effects with non-alliance connectivity (Figure 8). Larger airports, by virtue of their size and catchment areas, seem better able to sustain higher levels of connectivity over the period. What is also apparent from Figure 6 is the significant gap in average connectivity between the samples.

This sensitivity test demonstrates that the degree of remoteness does not necessarily imply that connectivity will be lower than average. Remoter airports, on average, achieve a marginally higher level of alliance connectivity, particularly after 2008. In terms of non-alliance connectivity, the differences between both samples are insignificant, particularly after 2008.

However, we are able to identify quite a strong and significant relationship between size and both alliance and non-alliance connectivity; showing that larger airports seemed better able to sustain higher levels of connectivity during the period. 


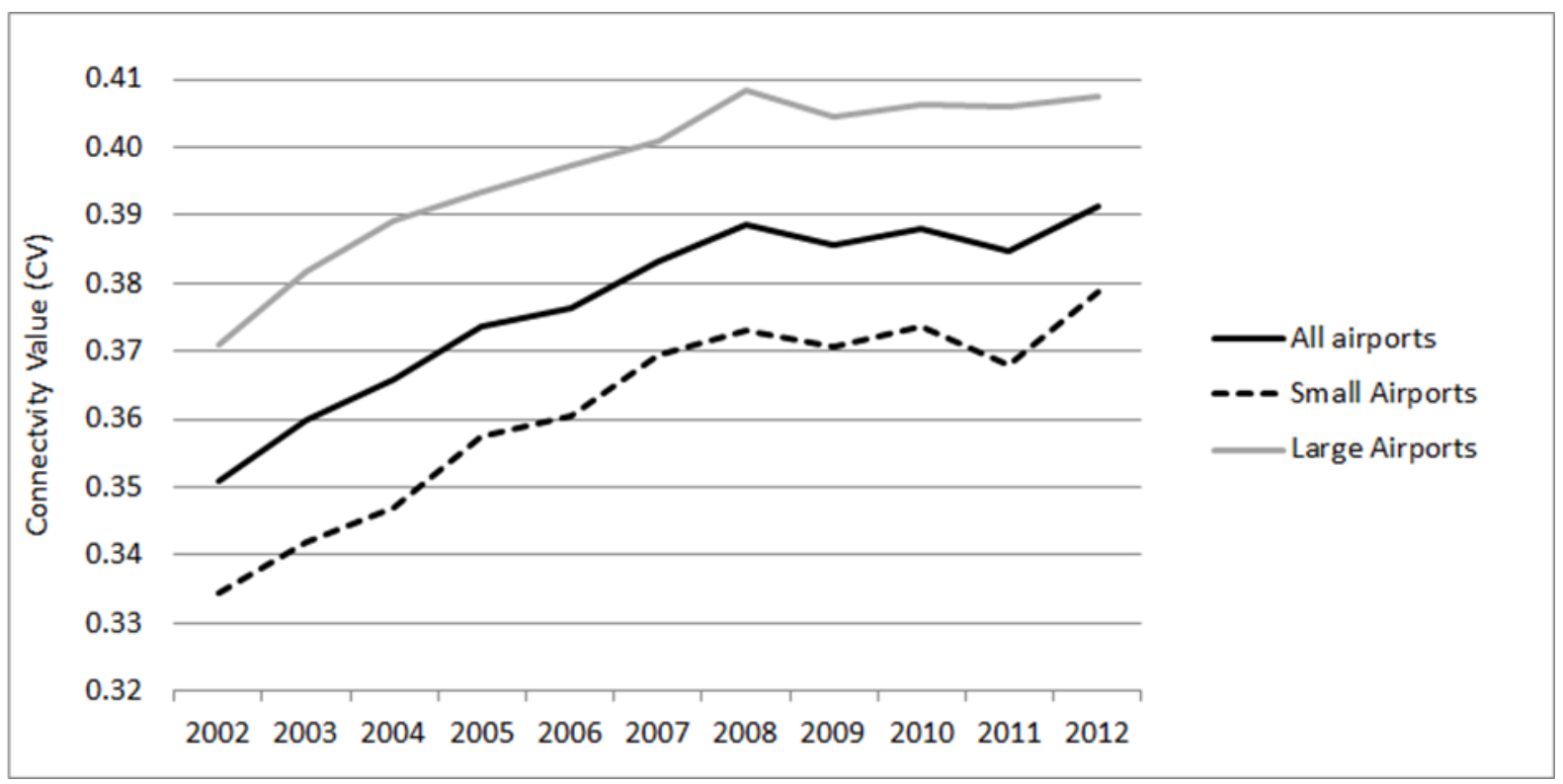

Figure 8. Average European Non-alliance Connectivity Values by Size of Airport, 2002-2012.

When analysing day-return schedules between regional and metropolitan hub airports, we found that when an LCC is the only operator on a route, MLDT times are usually insufficient to allow for a daily return. Secondly, LCCS only provide good MLDT times when the small airport functions as a network base; otherwise, MLDT times tend to be lower, disadvantaging passengers starting their journey from the region. Thirdly, on important FSNC routes, the entry of a LCC does not necessarily lead to significantly lower MLDT value for the FSNC services.

The different impacts of LCC entry on connectivity will have implications not only for airport and airline strategies but also for air transport policy. Indeed, not all small airports benefit from air transport liberalisation and competition in the same way (Suau-Sanchez et al., 2016a). In some instances, commercial and financial policies undertaken by local authorities can significantly increase traffic numbers (see for example Bel (2009) for the case of Girona Airport). However, local authorities may have to question the continued efficacy of offering LCCs very generous start-up incentive schemes without adequately considering the full connectivity implications (see also Halpern and Graham (2015) for a review of airport route development strategies). Our analysis shows that the convenience of day-trip itineraries may be adversely affected by LCC entry when the LCC is the only route operator. This is particularly true for the small airport outbound market, since the MLDT offered by the LCCs generally favours the inbound market due to the cost-minimising imperative to over-night aircraft at the main base. Local authorities should be advised of the need to appreciate these effects when evaluating whether to adopt route development initiatives in support of traffic growth at regional airports. Secondly, public service obligations (PSOs) have traditionally been used to guarantee services and connections in remote and small airports. However, as highlighted by Williams and Pagliari (2004) in Europe there is considerable variation in the extent and way in which countries have adopted the PSO mechanism. Such an approach hinges on the 
quiescence of national governments and their civil aviation regulators as to whether sufficient benefits are likely to accrue from what is, in effect, regulatory intervention in liberalised markets.

Our results support the idea that smaller airport connectivity is highly dependent on having FSNC services on key routes to hubs where both European and global destinations can be accessed through seamless and coordinated schedules. This can support the case for PSO intervention. However, we also demonstrate the potential of non-alliance connectivity that could be exploited through market mechanisms offering opportunities for airports with LCC bases to facilitate connections between flights. Some airport operators have already exploited this opportunity such as the "Fly Via Milano" booking platform operated by Milan Malpensa and the more recentlyestablished Gatwick Connects, which also provides connection insurance and a luggage tracker. Whilst it is still too early to judge whether these initiatives have been successful, they represent a serious attempt by airports that host LCC bases to secure additional revenue from the passengers that are already self-connecting and to expand beyond their local market. Some studies have measured the potential for self-connectivity using airline schedule data (Malighetti et al., 2008; Fichert and Klophaus ,2016; Maertens et al., 2016), which has been confirmed by other studies that use demand datasets (Suau-Sanchez, et al., 2016b). The limited literature on this topic seems to indicate so far that this could indeed facilitate and foster connectivity for smaller airports where FSNCs are not always present.

Future trends in connectivity at small airports are likely to be shaped by the extent to which both airports and airlines are able to become sufficiently innovative. In this regard, the evolution of both FSNC and LCC business models can be one of the main drivers in the future connectivity evolution at small airports. On the one hand, consolidation and network re-structuring by FSNC, driven by the need to improve profitability, means that small airport FSNC connections to major hubs will continue to be vulnerable to service withdrawal. In many cases, these services can be operated by regional airline affiliates who have both the appropriate equipment and cost structure to operate these services profitably. However, LCCS are at an advantage because they typically enjoy lower-seat costs than regional airlines in short-haul markets. Regional airlines are therefore vulnerable to being displaced by LCCS, potentially offering less connectivity to the small airport. On the other hand, the evolution of the LCC model means that their network characteristics are also changing. Fageda et al. (2015) highlight that hybrid LCCs (i.e., offering connecting flights and/or fare bundles) tend to operate in denser routes and also in routes that have a hub airport as an end-point. Size in an important element in our results because the route density problem and the limits of the organic growth of the archetypical point-to-point LCC (de Wit and Zuidberg, 2012) is forcing LCCs to consider alternative strategies. This may offer a new challenge to smaller airports and thinner markets. However, there are substantial opportunities in mid-sized markets and airports that are able to generate and sustain more viable demand to key hubs.

Also, some FSNCs have established LCC subsidiaries as a more sustainable business model to serve regional markets. These subsidiaries are not completely disconnected from their parent companies 
(e.g., Vueling and Iberia, Germanwings and Lufthansa) where schedules are coordinated and hub transfers facilitated, making it possible for small airports to maintain connectivity to both European and global markets. This suggests that integration of LCC and FSNC networks is possible and that traditional demarcations and inhibitions may no longer be relevant in all cases.

Further research connectivity at small airports could also add price and affordability assessments of possible travel options, as well as a more detailed quality analysis based on connection times.

\section{References}

Adikariwattage, V., de Barros, A., Wirasinghe, S., Ruwanpura, J., 2012. Airport classification criteria based on passenger characteristics and terminal size. Journal of Air Transport Management 24, 3641.

Alderighi, M., Cento, A., Nijkamp, P., Rietveld, P., 2012. Competition in the European aviation market: the entry of low-cost airlines. Journal of Transport Geography 24, 223-233.

Arend, M., Bruns, A., McCurry, J.W., 2004. The 2004 Global Infrastructure Report. Site Selection Magazine (September Issue), 580e5901.

Bel, G., 2009. How to compete for a place in the world with a hand tied behind your back: The case of air transport services in Girona. Tourism Management 30, 522-529.

Bel, G., Fageda, X., 2008. Getting there fast: globalization, intercontinental flights and location of headquarters. Journal of Economic Geography 8, 471-495.

Brueckner, J.K., 2003. Airline traffic and economic development. Urban Studies 40, 1455-1469.

Bowen, J., 2000. Airline hubs in Southeast Asia: national economic development and nodal accessibility. Journal of Transport Geography 8, 25-41.

Burghouwt, G., 2007. Airline Network Development in Europe and its Implications for Airport Planning. Ashgate, Hampshire.

Burghouwt, G., Hakfoort, J., 2001. The evolution of the European aviation network, 1990-1998. Journal of Air Transport Management 7, 311-318.

Burghouwt, G., de Wit, J., 2005. Temporal configurations of European airline networks. Journal of Air Transport Management 11, 185-198.

Burghouwt, G., Redondi, R., 2013. Connectivity in air transport networks: an assessment of models and applications. Journal of Transport Economics and Policy 47, 35-53.

Button, K., 2002. Debunking some common myths about airport hubs. Journal of Air Transport Management 8, 177-188.

Castillo-Manzano, J.L., Marchena-Gomez, M., 2011. Analysis of determinants of airline choice: profiling the LCC passenger. Applied Economics Letters 18, 49-53.

Clark, WA., Huang, Y., Withers, S., 2003. Does commuting distance matter?: Commuting tolerance and residential change. Regional Science Urban Economics, 199-211.

Copenhagen Economics, 2012. Airport Competition in Europe. Copenhagen Economics and ACl Europe, Copenhagen.

Danesi, A., 2006. Measuring airline hub timetable co-ordination and connectivity: definition of a new index and application to a sample of European hubs. Eur.Transp. 34, 54-74. 
Dash Nelson, G., Rae, A., 2016. An economic geography of the United States: From commuters to Megaregions. PLoS ONE 11(11): e0166083.

Derudder, B., Devriendt, L., Witlox, F., 2010. A spatial analysis of multiple airport cities. Journal of Transport Geography 18, 345-353.

Dobruszkes, F., 2013. The geography of European low-cost airline networks: a contemporary analysis. Journal of Transport Geography 28, 75-88.

Doganis, R., 2010. Flying off Course: the Economics of International Airlines, fourth ed., Routledge. London.

Fageda, X., Fernandez-Villadangos, L., 2009. Triggering competition in the Spanish airline market: the role of Airport capacity and low-cost carriers. Journal of Air transport Management 15, 36-40.

Fageda, X., Flores-Fillol, R., 2012. Air services on thin routes: regional versus low-cost airlines. Regional Science and Urban Economics 42, 702-714.

Fageda, X., Suau-Sanchez, P., Mason, K.J., 2015. The evolving low-cost Business model: Network implications of fare bundling and connecting flights in Europe. Journal of Air Transport Management 42, 289-296.

Fichert, F., Klophaus, R., 2016. Self-connecting, codesharing and hubbing among European LCCs: from point-to-point to connections? Research in Transportation Business \& Management 21, 94-98.

Florida, R., Mellander, C., Holgersson, T., 2015. Up in the air: the role of airports for regional economic development. Annals of Regional Science 54, 197-214.

Gaspar J, Glaeser, E.L., 1998. Information technology and the future of cities. Journal of Urban Economics 43, 136-156.

Goetz, A.R., 1992. Air passenger transportation and growth in the US urban system, 1950-1987. Growth and Change 23, 217-238.

Guida, M., Maria, F., 2007. Topology of the Italian airport network: a scale-free small-world network with a fractal structure? Chaos Solitons Fractals 31, 527-536.

Guimerà, R., Mossa, S., Turtschi, A., Amaral, L.A.N., 2005. The worldwide air transportation network: Anomalous centrality, community structure, and cities' global roles. Proceedings of the National Academy of Sciences USA 102 (22), 7794-7799.

Hall, P., 2009. Looking backward, looking forward: the city region of the mid-21st century. Regional Studies 43, 803-817.

Halpern, N., Bråthen, S., 2011. Impact of airports on regional accessibility and social development. Journal of Transport Geography 19, 1145-1154.

Halpern, N., Graham, A., 2015. Airport route development: A survey of current practice. Tourism Management 46, 213-221.

Hess, S., Polak, J.W., 2005. Mixed logit modelling of airport choice in multi-airport regions. Journal of Air Transport Management 11, 59-68.

Hess, S., Polak, J.W., 2006. Exploring the potential for cross-nesting structures in airport-choice analysis: a case study of the Greater London area. Transportation Research Part E 42, 63-81.

Jia, T., Jiang, B., 2012. Building and analyzing the US airport network based on en route location information. Physica A 391, 4031-4042.

Kasarda, J.D., 2000. Logistics and the rise of aerotropolis. Real Estate Issues, Winter 2000/2001, $43 e 48$. 
Knippenberger, U., 2010. Airport-region governance. In: Knippenberger, U., Wall, A., (Eds), Airports in Cities and Regions: Research and Practice. Karlsruhe: KIT Publishing, pp 101-111.

Lian, J.I., Rønnevik, J., 2011. Airport competition - Regional airports losing ground to main airports. Journal of Transport Geography 19, 85-92,

Lieshout, R., 2012. Measuring the size of an airport's catchment area. Journal of Transport Geography 25, 27-34.

Lieshout, R., Malighetti, P., Redondi, R., Burghouwt, G., 2016. The competitive landscape of air transport in Europe. Journal of Transport Geography 50, 68-82.

Malighetti, P., Paleari, S., Redondi, R., 2008. Connectivity of the European airport network: "self-help hubbing" and business implications. Journal of Air Transport Management 14, 53-65.

Matsumoto, H., Veldhuis, J., de Wit, J., Burghouwt, G., 2008. Network performance, hub connectivity potential, and competitive position of primary airports in Asia/Pacific region. In: Proceeding of the Air Transport Research Society Conference, Athens, June 2008.

Maertens, S., Pabst, H., Grimme, W., 2016. The scope for low-cost connecting services in Europe - Is self-hubbing only the beginning? Research in Transportation Business \& Management 21, 84-93.

Merkert, R., Mangia, L., 2014. Efficiency of Italian and Norwegian airports: A matter of management or of the level of competition in remote regions? Transportation Research Part A: Policy and Practice $62,30-38$.

Nassiri, H., Rezaei, A., 2012. An itinerary choice in a low-frequency market: A decision rule approach. Journal of Air Transport Management 18, 34-37.

Niesse, H., Grimme, W., 2013. How to measure airport connectivity? Average quickest travel time as indicator. In: Proceedings of the Air Transport Research Society Conference, Bergamo, June 2013.

Office of National Statistics, 2014. 2011 Census Analysis. Distance Travelled to Work. UK Titchfield.

OAG, 2016. Self-Connection: The Rise and Roadblocks of a Growing Travel Booking Strategy. OAG Reports.

O'Connell, J.F., Williams, G., 2005. Passengers' perceptions of low cost airlines and full service carriers: a case study involving Ryanair, Aer Lingus, Air Asia and Malaysian Airlines. Journal of Air Transport Management 11, 259-272.

Pagliari, R., 2003. The impact of airline franchising on air Service provision in the Highlands and Islands of Scotland. Journal of Transport Geography 11, 117-129.

Paleari, S., Redondi, R., Malighetti, P., 2010. A comparative study of airport connectivity in China, Europe and US: Which network provides the best service to passengers? Transportation Research Part E 46, 198-210.

Pels, E., Nijkamp, P., Rietveld, P., 2001. Airport and airline choice in a multi-airport region: an empirical analysis for the San Francisco bay area. Regional Studies 35, 1-9.

Pels, E., Nijkamp, P., Rietveld, P., 2003. Access to and competition between airports: a case study for the San Francisco Bay Area. Transportation Research Part A 37, 71-83.

Rae, A., 2016. The geography of travel to work in England and Wales: Extracts from the 2011 Census. Applied Spatial Analysis and Policy, 1-17.

Rapino, M., Fields, A. 2012. Mega commuting in the US: Time and distance in defining long commutes using the 2006-2010 American Community Survey. Association for Public Policy Analysis and Management (US) Fall Conference. 
Redondi, R., Malighetti, P., Paleari, Stefano, 2013. European connectivity: the role played by small airports. Journal of Transport Geography 29, 86-94.

Reynolds-Feighan, A., McLay, P., 2006. Accessibility and attractiveness of European airports: a simple small community perspective. Journal of Air Transport Management 12, 313-323.

Rodríguez-Déniz, H., 2012. Using SAS to Measure Airport Connectivity: An Application of Weighted Betweeness Centrality for the FAA National Plan of Integrated Airport Systems (NPIAS). In: Proceedings of the SAS Global Forum 2012, Paper 162-2012.

Rodríguez-Déniz, H., Suau-Sanchez, P., Voltes-Dorta, A., 2013. Classifying airports according to their hub dimensions: an application to the US domestic network. Journal of Transport Geography 33, 188-195.

Sapre M., Parekh N., 2011. Analysis of centrality measures of airport network of India. In: Kuznetsov S.O. et al. (Eds.), Proceedings of the International Conference on Pattern Recognition and Machine Intelligence (PReMI 2011), Vol. 6744, 2011, 376-381.

Salanti, A., Malighetti, P., Redondi, R., 2012. Low-cost pricing strategies in leisure markets. Tourism Management 33, 249-256.

Shaw, S., 1993. Hub structures of major US passenger airlines. Journal of Transport Geography 1, 4758.

Shaw, S., Ivy, R., 1994. Airline mergers and their effect on network structure. Journal of Transport Geography 2, 234-246.

Suau-Sanchez, P., Burghouwt, G., 2012. Connectivity levels and the competitive position of Spanish airports and Iberia's network rationalization strategy, 2001-2007. Journal of Air Transport Management 18, 47-53.

Suau-Sanchez, P., Burghouwt, G., Fageda, X., 2016a. Reinterpreting EU air transport deregulation: a disaggregated analysis of the spatial distribution of traffic in Europe, 1990-2009. Tijdschrift voor Economische en Sociale Geografie 107, 48-65.

Suau-Sanchez, P., Burghouwt, G., Pallares-Barbera, M., 2014. An appraisal of the CORINE land cover database in airport catchment area analysis using a GIS approach. Journal of Air Transport Management 34, 12-16.

Suau-Sanchez, P., Voltes-Dorta, A., Rodriguez-Deniz, H., 2015. Regulatory airport classification in the US: The role of international markets. Transport Policy 37, 157-166.

Suau-Sanchez, P., Voltes-Dorta, A., Rodriguez-Deniz, H., 2016b. "Measuring the potential for selfconnectivity in global air transport markets: Implications for airports and airlines. Journal of Transport Geography 57, 70-82.

Van de Vijver, E., Derudder, B., Witlox, F., 2014. Exploring causality in trade and air passenger travel relationships: the case of Asia-Pacific, 1980-2010. Journal of Transport Geography 34, 142-150.

Van Wijk, M., 2007. Airports as City Ports in the City-region. In: Netherlands Geographical Studies, vol. 353. Faculteit Geowetenschappen Universiteit Utrecht.

Veldhuis, J., 1997. The competitive position of airline networks. Journal of Air Transport Management 3, 181-188.

Wang, J., Mo, H., Wang, F., Jin, F., 2011. Exploring the network structure and nodal centrality of China's air transport network: a complex network approach. Journal of Transport Geography 19, 712-721.

Williams, G., Bråthen, S., 2010. Air Transport provision in remoter regions. Ashgate, Surrey. 
Williams, G., Pagliari, R., 2004. A comparative analysis of the application and use of public service obligations in air transport within the EU. Transport Policy 11, 55-66.

Windle, R., Dresner, M., 1999. Competitive responses to low cost carrier entry. Transportation Research Part E: Logistics and Transportation Review 35, 59-75.

Wit, J.de, Zuidberg, J., 2012. The growth limits of the low cost carrier model. Journal of Air Transport Management 14, 17-23.

Zeng, X., Tang, X., Jiang, K., 2011. Empirical study of Chinese airline network structure based on complex network theory. J. Transp. Syst. Eng. Inf. Technol. 11 (6), 175-181.

Zhang, Y., Xie, Y., 2005. Small community airport choice behaviour analysis: a case study of GTR. Journal of Air Transport Management 11, 442-447. 
Low-cost carrier entry at small European airports: Low-cost carrier effects on network connectivity and self-transfer potential

\section{Zeigler, Patrick}

Elsevier

Zeigler P, Pagliari R, Suau-Sanchez P, et al., (2017) Low-cost carrier entry at small European airports: Low-cost carrier effects on network connectivity and self-transfer potential. Journal of Transport Geography, Volume 60, April 2017, pp. 68-79

https://doi.org/10.1016/j.isatra.2020.05.001

Downloaded from Cranfield Library Services E-Repository 